\title{
Mechanical Properties and Thermal Behaviour of LLDPE/MWNTs Nanocomposites
}

\author{
Tai Jin-hua ${ }^{\mathrm{a}}$, Liu Guo-qin ${ }^{\mathrm{b} *}$, Caiyi Huang ${ }^{\mathrm{c}}$, Shangguan Lin-jian ${ }^{\mathrm{a}}$ \\ ${ }^{a}$ School of Mechanical Engineering, North China University of Water Conservancy and Electric Power, \\ Zhengzhou, 450011, China \\ ${ }^{\mathrm{b}}$ College of Material Science and Engineering, Henan University of Technology, \\ Zhengzhou, 450001, China \\ 'Ningbo University's Faculty of Science, Ningbo University, Ningbo 315211, China
}

Received: August 18, 2011; Revised: July 27, 2012

\begin{abstract}
Multi-walled carbon nanotubes (MWNTs) were incorporated into a linear low-density polyethylene (LLDPE) matrix through using screw extrusion and injection technique. The effect of different weight percent loadings of MWNTs on the morphology, mechanical, and thermal of LLDPE/MWNTs nanocomposite had been investigated. It was found that, at low concentration of MWNTs, it could uniformly disperse into a linear low-density polyethylene matrix and provide LLDPE/MWNTs nanocomposites much improved mechanical properties. Thermal analysis showed that a clear improvement of thermal stability for LLDPE/MWNTs nanocomposites increased with increasing MWNTs content.
\end{abstract}

Keywords: LLDPE, MWNTs, mechanical properties, thermal behavior

\section{Introduction}

Polymer nanocomposites, i.e. polymer formed with nano-sized fillers, display superior properties at lower loading than conventional composites and have attracted more and more attention because of their many advantages such as flexible features, easy processing, and lightweight ${ }^{1-11}$, especially polymers/carbon nanotubes (CNTs) nanocomposites ${ }^{12-15}$. CNTs are ideal fillers for incorporation into composite systems and show high Young modulus, tensile strength, electrical conductivity and thermal conductivity. Therefore, polymers/CNTs nanocomposites could use for the development of advanced multifunction materials, due to physicochemical properties, their high aspect ratio, and extremely large surface areas, together with the need for only small volume fractions to obtain desired properties ${ }^{16-19}$.

It is well known that CNTs can exist in the form of single-walled carbon nanotubes (SWNTs) and multi-walled carbon nanotubes (MWNTs). They can both be synthesized by three techniques: laser ablation, arc discharge and chemical vapour decomposition $(\mathrm{CVD})^{20}$. In general, CVD is the most commonly used method for mass production of different types of CNTs. Although SWNTs offer the opportunity for much lower loading versus MWNTs to achieve the same electrical properties, enhancing mechanical properties even further ${ }^{21}$, MWNTs are extensively used, due to lower unit cost, greater availability and fewer dispersion challenges compared with SWNTs.

Linear low density polyethylene (LLDPE) is a commodity polymer, cheap, versatile, with widely uses in a variety of forms. Enhancing of LLDPE properties should

*e-mail: mikepolymer@126.com be of interest in order to expand its application fields. In this study, LLDPE/MWNTs nanocomposites are fabricated by using traditional twin-screw extruder and injection machine; to improve LLDPE mechanical properties and thermal stability, and the effect of MWNTs loading on mechanical properties is investigated.

\section{Experimental}

\subsection{Material}

MWNTs were supplied by Shenzhen Nano-Technologies Port Co. Ltd., China, with a purity of above $94 \%$, average length of microns, and surface area of $4.26 \mathrm{~m}^{2} / \mathrm{g}$. Linear low-density polyethylene (LLDPE, with number-average molecular weight of $20000 \mathrm{~g} . \mathrm{mol}^{-1}$ ) was supplied by Daqing Petroleum \& Chemical Co., and used without any further treatment. Polyethylene glycol (PEG, Aldrich, $\mathrm{M}_{\mathrm{n}}$ $=20000$ ) was dried by heating at $70{ }^{\circ} \mathrm{C}$ for 7 hours under vacuum, used as an organic dispersant, and also played a role of a plasticizer. 3-(trimethoxysilyl) propyl methacrylate (KH-570) was used as a coupling agent and paraffin wax (chemical grade) was used as a lubricant.

\subsection{Preparation of LLDPE/MWNTs nanocomposites}

Firstly, MWNTs were immersed in $3 \mathrm{~mol} . \mathrm{L}^{-1}$ nitric acid $\left(\mathrm{HNO}_{3}\right)$ and refluxed for 8 hours, subsequently washed with distilled water until the $\mathrm{pH}$ of MWNTs solution was ca. 7, finally obtained after dried in a vacuum oven at $90{ }^{\circ} \mathrm{C}$ for 40 hours. 
Adding the gained MWNTs, PEG and KH-570 into ethanol, the mixtures were sonicated using a bath sonicator for 1 hour. Then they were dried in a vacuum oven at $65^{\circ} \mathrm{C}$ for 24 hours to remove ethanol, which were mixed with LLDPE and $0.1 \mathrm{wt}$. (\%) of paraffin wax.

The above mixtures were extruded with a TE-35 co-rotating twin-screw extruder (Coperion Machinery Co., Ltd., China). The test specimens were molded using an injection machine (TTI-80, Tonghua machinery Ltd., Canton, China) with a screw of $33.0 \mathrm{~mm}$ in diameter, and L/D ratio of 20 .

\subsection{Characterizations}

MWNTs size analysis was performed on a Microtrac S3000 analyzer (Microtrac Software Co., USA). Thermogravimetric analysis (TGA) measurement was performed using TGA-7 (Perkin-Elmer). The thermal analyses were carried out with a differential scanning calorimeter (DSC, DuPont 9900) over a temperature range from $70^{\circ} \mathrm{C}$ to $155^{\circ} \mathrm{C}$ at a heating rate of $10^{\circ} \mathrm{C} / \mathrm{min}$, purged with nitrogen gas, and quenched with liquid nitrogen. The cell was calibrated using an indium standard; the weight of the sample was 5-10 mg. The tensile and flexural properties of the nanocomposites were measured on an Instron testing machine (model 4302). The notched Izod impact tests were performed with XJ-40A pendulum apparatus (Wuzhong Material Testing Machine Factory, Jiangsu, China). SEM observation was carried out with a JSM-5900LV scanning electron microscopy.

\section{Result and Discussion}

\subsection{SEM observation}

The diameter distribution of as-received MWNTs is measured, as shown in Figure 1. The diameter of 93\% MWNTs is smaller than $100 \mathrm{~nm}$ with average diameters $=68 \mathrm{~nm}$, and about $0.8 \%$ large than $200 \mathrm{~nm}$.

It is well known that the dispersion of CNTs in the polymer matrix and the interfacial interactions between the polymer matrix and nanotubes are the key factors to ultimately determine many properties of polymers/CNTs

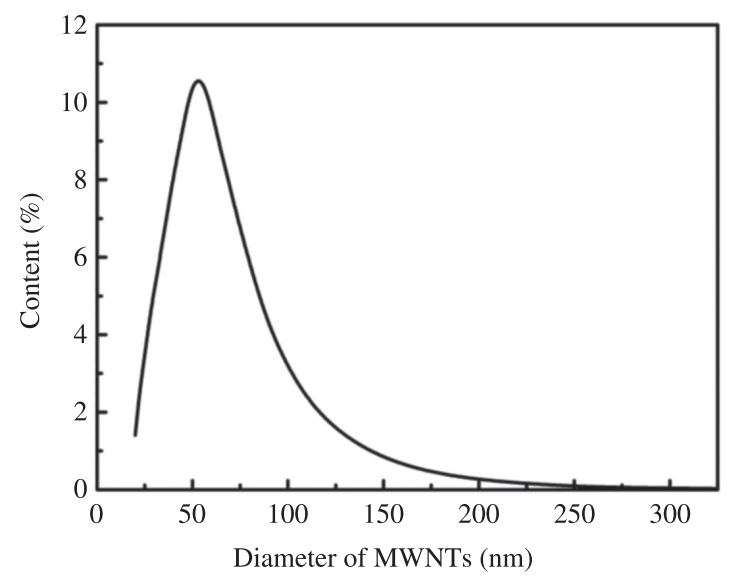

Figure 1. Diameter distribution of MWNTs. nanocomposites. A uniform dispersion of CNTs and strong interfacial interactions between them can effectively improve the thermal, solid mechanical, adhesive, and electrical performances of the nanocomposite. To reveal dispersion of MWNTs in the LLDPE matrix, SEM observations were performed for cryo-fractured surfaces of LLDPE/MWNTs nanocomposites, as shown in Figures 2a-e. A fibrous fractured surface is observed due to the elongation at break of LLDPE/MWNTs nanocomposites; the random dispersed bright dots because of MWNTs high conductivity are the ends of the broken carbon nanotubes ${ }^{22}$. In addition, it is found that some MWNTs are broken apart, and, as a result of poor interfacial adhesion, some MWNTs are pulled out of the matrix before the breakage, forming caves on the fractured surface; moreover, other MWNTs are observed with their one end still strongly embedded in the LLDPE matrix as an inset. Such interesting and typical breakage phenomenon of the MWNTs indicates that a strong interfacial adhesion exists between MWNTs and LLDPE matrix and that the load transfer takes place efficiently from the matrix to the nanotubes. The strong interfacial adhesion is usually responsible for the significant enhancement of the mechanical propertie ${ }^{23}$.

At low concentration of MWNTs, from Figures 2a-c, it can be seen that the bright dots (i.e., MWNTs) embedded in the LLDPE matrix and the caves (i.e., MWNTs) pulled out from the LLDPE matrix are well dispersed; however, with an increase in MWNTs concentration, from Figures 2d, e), a nonuniform dispersion of MWNTs is observed in the nanocomposites, and a large aggregate of MWNTs having a diameter of over $500 \mathrm{~nm}$ is presented; while in the case of pristine MWNTs, its diameter is about $30-40 \mathrm{~nm}$, as shown in Figure 1. Those indicate that the MWNTs were dispersed as nanotubes aggregates due to the imperfect mixing of the masterbatch.

When the content of MWNTs is no more than $1.0 \mathrm{wt} .(\%)$, owing to producing carboxylic or hydroxylic groups on the surface of the MWNT by $\mathrm{HNO}_{3}$ treatment ${ }^{24,25}$, which ensures the high dispersion quality of the MWNTs and prevents the severe aggregation of MWNTs ${ }^{26,27}$, reasonably uniform distribution of the MWNTs is observed in Figures 2a-c. On the other hand, at compositions containing greater amounts of MWNTs, a small amount of aggregates is shown in Figures $2 d, e)$. These results are in good agreement with the results of $\mathrm{Wu}$ et al. ${ }^{28}$ and Bikiaris et al. ${ }^{29}$ who reported that increasing the content of $\mathrm{SiO}_{2}$ leads to larger agglomerates; this is also the case in LLDPE/MWNTs nanocomposites. In fact, there are more or less agglomerates of MWNTs formed in Figure 2. It is worth nothing, due to the strong interaction among the nanoparticles, the limited shear force provided by the mixing device and the high melt viscosity of polymer melts, especially the high viscosity of the LLDPE melt (MFI about $1 \mathrm{~g} / 10 \mathrm{~min})^{30}$, might be impossible to pursue an efficient nanoscale dispersion of MWNTs.

\subsection{Mechanical property of LLDPE/MWNTs nanocomposites}

There are many researches on the effectiveness of nanoparticles to bear impact toughness. The amounts of MWNTs have great effects on the impact strength of 


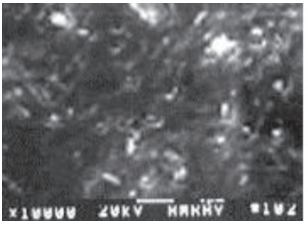

(a)

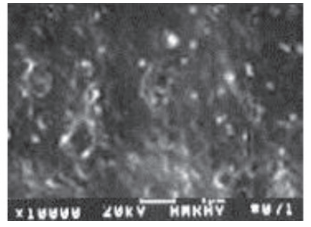

(b)

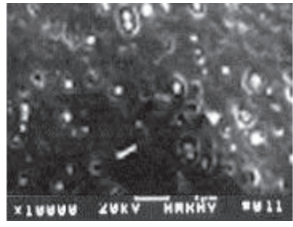

(c)

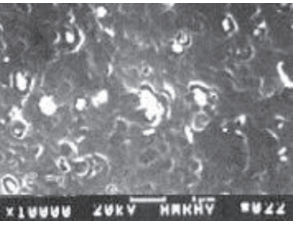

(d)

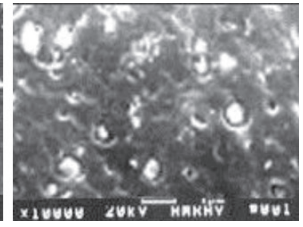

(e)

Figure 2. SEM images of LLDPE/MWNTs nanocomposites. a) LLDPE/0.3 wt. (\%) MWNTs, b) LLDPE/0.5 wt. (\%) MWNTs, c) LLDPE/1.0 wt. (\%) MWNTs, d) LLDPE/2.0 wt. (\%) MWNTs, and e) LLDPE/3.0 wt. (\%) MWNTs.

LLDPE/MWNTs nanocomposites in Figure 3. The Izod impact strength of notched specimen initially increases with the increasing of MWNTS, and reaches the maximum value $\left(37.15 \mathrm{~kJ} . \mathrm{m}^{-2}\right)$ at MWNT content of $1.0 \mathrm{wt} .(\%)$, a $239 \%$ increase compared with that of pure LLDPE. The measured mechanical properties truly reflect the homogeneous dispersion of MWNTs in polymer matrix leads to improving impact strength, as shown in Figures 2a-c. This is because the size of the intercalated MWNTs is in the similar order as that of macromolecular segments, and the increased free volume in the composites makes it possible for the segments to move when composites are subjected to an impact force ${ }^{31}$. But at high MWNTs contents exceeding 1.0 wt. (\%), they tend to agglomerate, as shown in Figures 2d, e, and act as stress concentrators, which may decrease the impact strength.

In order to evaluate the reinforcing effect of MWNTs into the LLDPE matrix, mechanical properties during extension were measured. In Figure 4, the variation of tensile strength for LLDPE/MWNTs nanocomposites is shown as a function of MWNTs content. The increase of tensile strength is observed for MWNTs contents up to $1.0 \mathrm{wt}$. (\%), reaching $22 \%$ in regard to the initial value; the reduction in tensile strength observed for MWNTs concentrations higher than $1 \mathrm{wt}$. (\%) should be rather associated with MWNTs aggregation, which increased with increasing MWNTs amounts, as was observed in SEM micrographs discussed above. It is obvious that MWNTs content plays an important role as far as their efficiency in acting as reinforcement agents is concerned.

In the case of Young's modulus, its variation for LLDPE nanocomposites at different MWNTs concentrations is shown in Figure 5. An increase in modulus with filler loading is observed for LLDPE/MWNTs nanocomposites, which reaches up to 54\% compared to neat LLDPE and indicates increased stiffness due to the rising filler content. A change of deformation behavior from ductile to more brittle occurs at higher contents of MWNTs.

The results of elongation at the break point measurements are presented in Figure 6. It is clear that incorporation of MWNTs initially has a negative effect on the elongation at the break point and a greater decrease reaches up to 53\% compared to neat LLDPE; however, as MWNTs concentrations is more than $1 \mathrm{wt}$. (\%), the elongation at the break increases with increasing MWNTs amounts. It seems that, at MWNTs content of no more than $1.0 \mathrm{wt}$. (\%), its dispersion is uniform; meanwhile, MWNTs, which are rigid, almost no elongation, and included in LLDPE matrix, behave like physical cross-linking points and restrict the

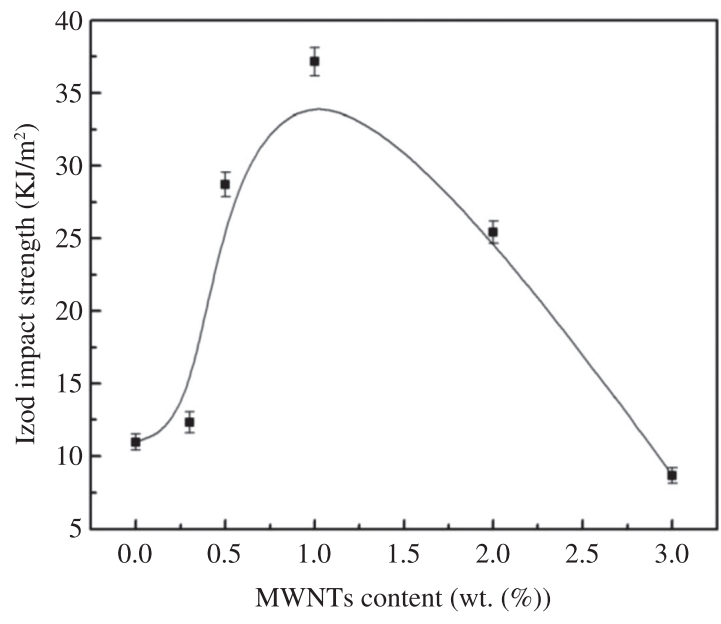

Figure 3. Izod impact strength of the LLDPE nanocomposites with different MWNTs content.

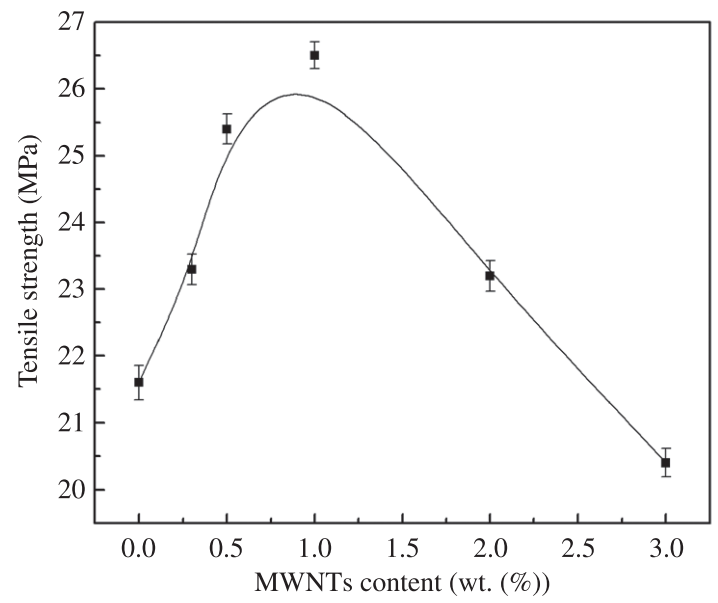

Figure 4. Tensile strength of LLDPE nanocomposites as a function of MWNTs content.

movement of polymer chains, and have this property in the final composite material. As a result they inhibit the elongation of the nanocomposite, making it less ductile. On the other hand, when the concentration is higher than $1.0 \mathrm{wt}$. (\%), the elongation at the break increases; this is because MWNTs agglomerate are formed in the matrix (Figures 2d, e), resulting in a profoundly deleterious effect on the properties of LLDPE/MWNTs nanocomposites, for they induces premature fracture and frequently becomes sources of the secondary $\operatorname{crack}^{32}$. 


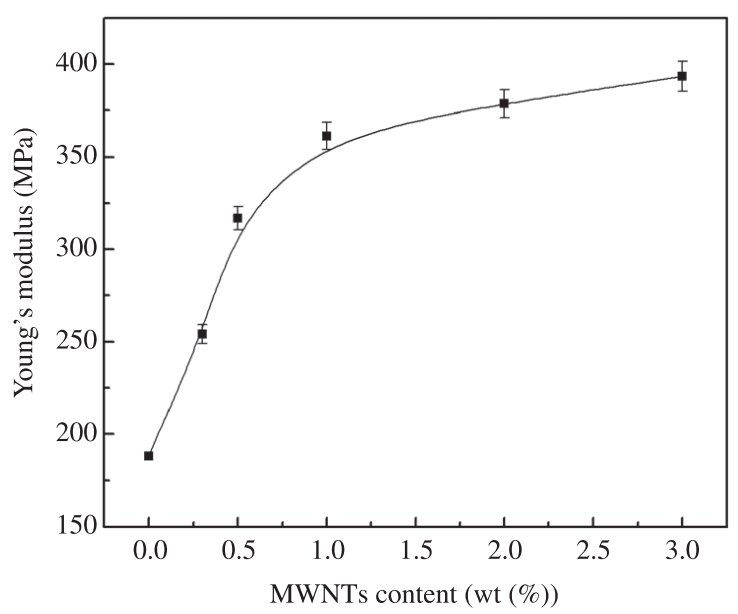

Figure 5. Young's modulus of LLDPE nanocomposites versus MWNTs content.

Sternstein et al. ${ }^{33}$, have primarily attributed the reinforcement mechanism of nano-filled polymer, to trapped entanglements that existed in the temporary bonding between polymer chains and the filler surface ${ }^{33}$, which has both near - and far-field effects on matrix chain motion, and plays the role of physical cross-linking network, thus leading to greatly enhanced modulus of matrix ${ }^{34}$; when load is transferred to the physical cross-linking network, the debonding (disentanglement) of chain segments from the filler surface facilitates the relaxation of the matrix entanglement structure, leading to the higher impact toughness. Therefore, following above analysis, we have gained not only a higher modulus but also higher impact toughness in LLDPE/MWNTs nanocomposites. On the other hand, the choice of suitable filler, as well as a suitable quantity, grain size and high compatibility with the polymer matrix, is a key factor for efficient toughening, which can accomplish improvement of polymer's mechanical properties, except elongation at break and toughness. On the addition of filler, the interface conditions for the brittle-ductile transition of matrix should be in accordance with the following requirements: (1) a strong adhesion should exist between the matrix and filler so that the stress is transferred through the interfacial area; and (2) the interfacial area should be a lower stiffness than the matrix and deform, thereby yielding prior to the matrix and inducing matrix yielding ${ }^{35}$. In our experiment, due to the poor interfacial bonding between MWNTs and LLDPE macromolecules, the interface stiffness is lower and the tensile strength reduces.

\subsection{Thermal properties}

It is of great interest to study the crystallization and melting behavior of neat LLDPE and its nanocomposites because crystal structures and crystallinity play significant roles in the mechanical and other properties of crystalline polymers. DSC analysis is a generally convenient method for analyzing first order transitions like melting and crystallization. Figure 7 shows the thermal diagram measured during both heating and cooling. The LLDPE/MWNTs nanocomposites possess a melting endothermic peak $\left(T_{m}\right)$

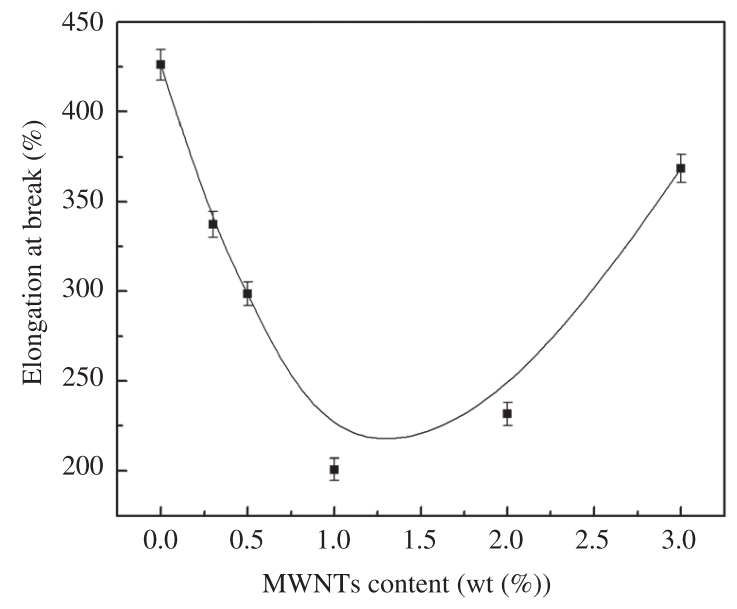

Figure 6. Elongation at break of LLDPE nanocomposites versus MWNTs content.

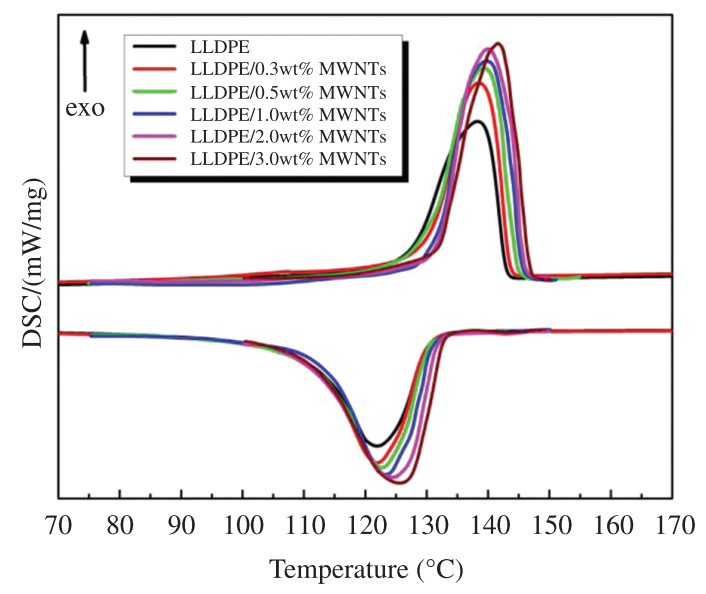

Figure 7. DSC scans of neat LLDPE and LLDPE/MWNTs nanocomposites with different MWNTs content.

during heating and a crystallization exothermal peak $\left(T_{c}\right)$ during cooling; it can be observed that $T_{m}$ and $T_{c}$ increase very slightly in the LLDPE/MWNTs nanocomposite compared with those in neat LLDPE, and increase with increase of MWNTs concentration, which indicates that the MWNTs presence does not prevent LLDPE crystallization and melting, and act as an nucleation reagent for the LLDPE crystallization; meanwhile, the crystallization enthalpy $\left(\Delta H_{c}\right)$ and melting enthalpy $\left(\Delta H_{m}\right)$ which are determined from the area under the exotherm and endotherm, are increased in the nanocomposites as compared with that of neat LLDPE. The incorporation of MWNTs enhances the crystallization of LLDPE in the nanocomposites compared with that of neat LLDPE, which should be attributed to the strong heterogeneous nucleation of MWNTs ${ }^{27}$.

Figure 8 shows TGA thermograms of neat LLDPE, MWNTs and LDPE/MWNTs nanocomposites. The decomposition temperature (onset of inflection) for neat LLDPE is lower than those of its nanocomposites, indicating that the thermal stability of nanocomposites has been 


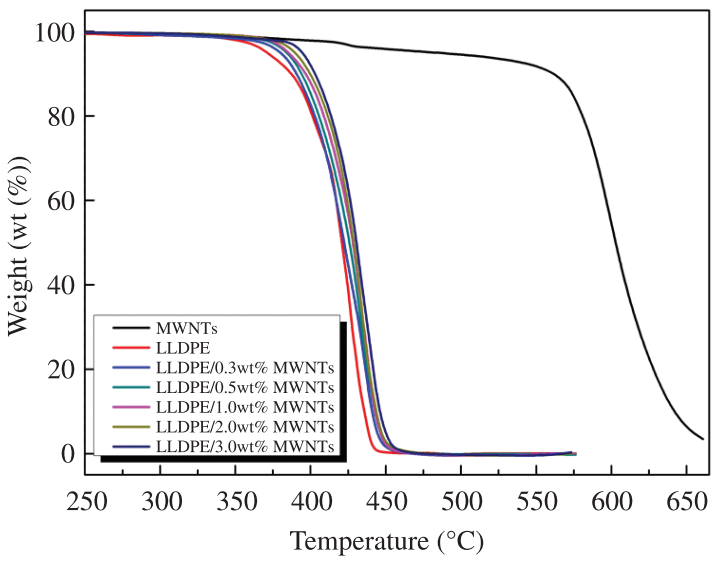

Figure 8. TGA curves of MWNTs, LLDPE and LLDPE/MWNTs nanocomposites.

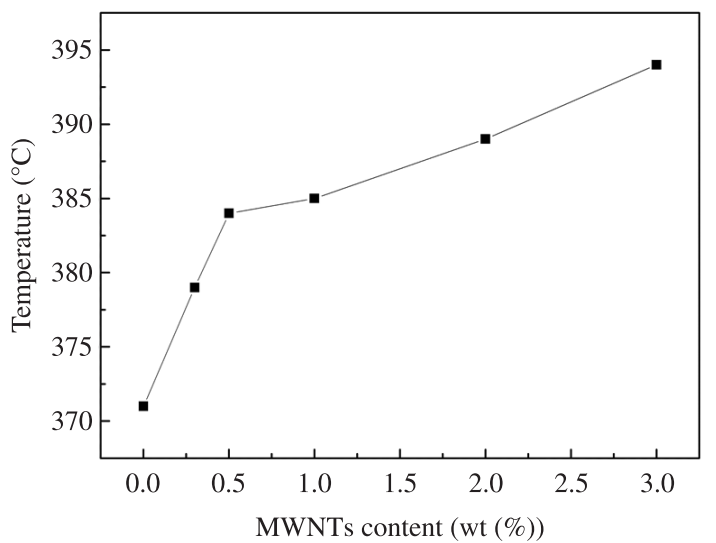

Figure 9. Decomposition temperature $\left(T_{d}, 5 \%\right.$ weight loss temperature) as a function of MWNTs loading.

improved because of addition of MWNTs. Besides that, the residual weight of LLDPE/MWNTs nanocomposites left increases steadily with the increase of MWNTs loading. As shown in Figure 8, the weight loss at $432{ }^{\circ} \mathrm{C}$ for neat LLDPE is about $85 \%$, whereas LLDPE/MWNTs nanocomposites are only around $58-72 \%$. This also indicates that the thermal stability of LLDPE is significantly improved on incorporation of MWNTs.

\section{References}

1. Chung DDL. Electromagnetic interference shielding effectiveness of carbon materials. Carbon. 2001; 39(2):279-285. http://dx.doi.org/10.1016/S0008-6223(00)00184-6

2. Chung DDL and Shui X. Submicron diameter nickel filaments and their polymer-matrix composites. Journal of Materials Science. 2000; 35(7):1773-1785. http://dx.doi. org/10.1023/A:1004784720338

3. Allaoui A, Bai S, Cheng HM and Bai JB. Mechanical and electrical properties of a MWCNT/epoxy composite.
Figure 9 shows the dependence of the decomposition temperature $\left(T_{d}, 5 \%\right.$ weight loss temperature) on MWNTs content. Neat LLDPE and pure MWNTs start to loss weight at $371{ }^{\circ} \mathrm{C}$ and $467{ }^{\circ} \mathrm{C}$, respectively. It can be seen that the overall thermal stability of LLDPE/MWNTs nanocomposites, compared with neat LLDPE, is clearly improved; in Figure 9, the addition of 0.5 wt. (\%) MWNTs causes the decomposition temperature of LLDPE increase more than $10^{\circ} \mathrm{C}$. The thermal stability of LLDPE/MWNTs nanocomposites may be closely related to following factors: the dispersion state and the loading content of MWNTs. The decomposition temperature of LLDPE/MWNTs nanocomposites increases slightly with increasing MWNTs loading content, probably due to the ease of compact char formation for the nanocomposites during the thermal degradation. On the other hand, high concentration MWNTs would definitely prevent its fine dispersion, and more aggregation or bundles could often be formed because of van der Waals force among the MWNTs, thus deteriorating the thermal stability of the nanocomposites. It is necessary to research the competing effect between the dispersion state and the loading content of MWNTs in depth.

\section{Conclusions}

Multi-walled carbon nanotubes (MWNTs) were dispersed into a linear low density polyethylene matrix through melt blending using twin-screw extruder with $0.3 \%$; $0.5 \% ; 1 \% ; 2 \%$ and $3 \%(\mathrm{wt} / \mathrm{wt}$ ) of MWNTs loadings.

Morphological analysis shows that, at low concentration of MWNTs, it is well dispersed; however, with an increase in MWNTs concentration, it is a nonuniform dispersion, and a large aggregate of MWNTs having a diameter of over $500 \mathrm{~nm}$ is formed. Mechanical properties showed that the Izod impact strength of notched specimen and the tensile strength initially increased with the increasing MWNTs content, and subsequently decrease with increasing MWNTs content. DSC analysis showed that $T_{m}$ and $T_{c}$ increased very slightly in the LLDPE/MWNTs nanocomposite compared with those in neat LLDPE, and increased with increase of MWNTs concentration. The analysis of thermal degradation in airflow showed a clear improvement of thermal stability for LLDPE/MWNTs nanocomposites, proportionally to MWNTs content.
Composites Science and Technology. 2002; 62(15):1993-1998. http://dx.doi.org/10.1016/S0266-3538(02)00129-X

4. Zou YB, Feng YC, Wang L and Liu XB. Processing and properties of MWNT/HDPE composites. Carbon. 2004; 42(2):271-277. http://dx.doi.org/10.1016/j.carbon.2003.10.028

5. Park SJ, Cho MS, Lim ST, Choi HJ and Jhon MS. Synthesis and dispersion characteristics of multi-walled carbon nanotube composites with poly(methyl methacrylate) prepared by in-Situ bulk polymerization. Macromolecular Rapid Communications. 2003; 24(18):1070-1073. http://dx.doi. org/10.1002/marc.200300089 
6. Yeh MK, Tai NH and Liu JH. Mechanical behavior of phenolic-based composites reinforced with multi-walled carbon nanotubes. Carbon. 2006; 44(1):1-9. http://dx.doi. org/10.1016/j.carbon.2005.07.005

7. Konyushenko EN, Stejskal J, Techova M, Hradil J, Kovarova $\mathrm{J}$, Prokes $\mathrm{J}$ et al. Multi-wall carbon nanotubes coated with polyaniline. Polymer. 2006; 47(16):5715-5723. http://dx.doi. org/10.1016/j.polymer.2006.05.059

8. Maity A and Biswas M. Recent Progress in Conducting Polymer, Mixed Polymer-Inorganic Hybrid Nanocomposites. Journal of Industrial and Engineering Chemistry. 2006; 12(3):311-351.

9. Grossiord N, Loos J, Regev O and Koning CE. Toolbox for Dispersing Carbon Nanotubes into Polymers To Get Conductive Nanocomposites. Chemistry of Materials. 2006; 18(5):1089-1099. http://dx.doi.org/10.1021/ cm051881h

10. Kim ST, Lim JY, Park BJ and Choi HJ. Dispersion-polymerized carbon nanotubepoly(methyl methacrylate) composite particles and their electrorheological characteristics. Macromolecular Chemistry and Physics. 2007; 208(5):514-519. http://dx.doi. org/10.1002/macp.200600543

11. Zhang FH, Wang RG, He XD, Wang $C$ and Ren LN. Interfacial shearing strength and reinforcing mechanisms of an epoxy composite reinforced using a carbon nanotube/carbon fiber hybrid. Journal of materials science. 2009; 44(13):3574-3577. http://dx.doi.org/10.1007/s10853-009-3484-x

12. Kearns JC and Shambaugh RL. Polypropylene fibers reinforced with carbon nanotubes. Journal of Applied Polymer Science. 2002; 86(8):2079-2084. http://dx.doi.org/10.1002/ app. 11160

13. Safadi B, Andrews R and Grulke EA. Multiwalled carbon nanotube polymer composites: Synthesis and characterization of thin films. Journal of Applied Polymer Science. 2002; 84(14):2660-2669. http://dx.doi.org/10.1002/ app. 10436

14. Tong X, Liu C, Cheng H, Zhao H, Yang F and Zhang X. Surface modification of single-walled carbon nanotubes with polyethylene via in situ Ziegler-Natta polymerization. Journal of Applied Polymer Science. 2004; 92(6):3697-3700. http:// dx.doi.org/10.1002/app.20306

15. Wang Y, Cheng R, Liang L and Wang Y. Study on the preparation and characterization of ultra-high molecular weight polyethylene-carbon nanotubes composite fiber. Composites Science and Technology. 2005; 65(5):793-797. http://dx.doi. org/10.1016/j.compscitech.2004.10.012

16. Gojny FH, Wichmann MHG, Fiedler B, Bauhofer W and Schulte K. Influence of nano-modification on the mechanical and electrical properties of conventional fibre-reinforced composites. Composites: Part A: Applied Science and Manufacturing. 2005; 36(11):1525-1535. http://dx.doi. org/10.1016/j.compositesa.2005.02.007

17. Poncharal P, Wang ZL, Ugarte D and De Heer WA. Electrostatic deflections and electromechanical resonances of carbon nanotubes. Science. 1999; 283(5407):1513-1516. PMid: 10066169 . http://dx.doi.org/10.1126/ science.283.5407.1513

18. Terrones M. Science and techology of the twenty-first century: synthesis, properties and applications of carbon nanotubes. Annual Reviews Materials Research. 2003; 33:419-501. http:// dx.doi.org/10.1146/annurev.matsci.33.012802.100255

19. Goh HW, Goh SH, Xu GQ, Pramoda KP and Zhang WD. Crystallization and dynamic mechanical behavior of double-C60-end-capped poly(ethylene oxide)/ multi-walled carbon nantube composites. Chemical Physics
Letters. 2003; 379(3-4):236-241. http://dx.doi.org/10.1016/j cplett.2003.08.018

20. Thostenson ET, Zhifeng R and Chan TW. Advances in the science and technology of carbon nanotubes and their composites: a review. Composites Science and Technology. 2001; 61(13):1899-1912. http://dx.doi. org/10.1016/S0266-3538(01)00094-X

21. Coleman JN, Khan U, Blau J and Gun'ko Y. Small but strong: A review of the mechanical properties of carbon nanotube-polymer composites. Carbon. 2006; 44(9):1624-1652. http://dx.doi. org/10.1016/j.carbon.2006.02.038

22. Chen D, Wang M, Zhang, WD and Liu T. Preparation and Characterization of Poly(vinylidene fluoride) Nanocomposites Containing Multiwalled Carbon Nanotubes. Journal of Applied Polymer Science. 2009; 113(1):644-650. http://dx.doi. org/10.1002/app.29311

23. Chen GX, Kim HS, Park BH and Yoon JS. Multi-walled carbon nanotubes reinforced nylon 6 composites. Polymer. 2006; 47(13):4760-4767. http://dx.doi.org/10.1016/j. polymer.2006.04.020

24. Kim ST, Choi H and Hong SM. Bulk polymerized polystyrene in the presence of multiwalled carbon nanotubes. Colloid \& Polymer Science. 2007; 285(5):593-598. http://dx.doi. org/10.1007/s00396-006-1599-z

25. Liu J, Rinzler AG, Dai H, Hafner JH, Bradley RK, Boul PJ et al. Fullerene Pipes. Science. 1998; 280(5367):1253-1256. PMid:9596576. http://dx.doi.org/10.1126/ science.280.5367.1253

26. Park SJ, Lim ST, Cho MS, Kim HM, Joo J and Choi HJ. Electrical properties of multi-walled carbon nanotube/ poly(methyl methacrylate) nanocomposite. Current Applied Physics. 2005; 5(4):302-304. http://dx.doi.org/10.1016/j. cap.2004.02.013

27. Zhao Y, Qiu Z and Yang W. Effect of functionalization of multiwalled nanotubes on the crystallization and hydrolytic degradation of biodegradable Poly(L-lactide). The Journal of Physical Chemistry B. 2008; 112(51):16461-16468. PMid:19055414. http://dx.doi.org/10.1021/jp805230e

28. Wu CL, Zhang MQ, Rong MZ and Friedrich K. Tensile performance improvement of low nanoparticles filled-polypropylene composites. Composites Science and Technology. 2002; 62(10-11):1327-1340. http://dx.doi. org/10.1016/S0266-3538(02)00079-9

29. Bikiaris DN, Vassiliou A, Pavlidou E and Karayannidis P. Compatibilisation effect of PP-g-MA copolymer on $\mathrm{iPP} / \mathrm{SiO}_{2}$ nanocomposites prepared by melt mixing. European Polymer Journal. 2005; 41(9):1965-1978. http://dx.doi.org/10.1016/j. eurpolymj.2005.03.008

30. Kontou E and Niaounakis M. Thermo-mechanical properties of LLDPE/SiO, nanocomposites. Polymer. 2006; 47(4):1267-1280. http://dx.doi.org/10.1016/j. polymer.2005.12.039

31. Liang GD, Xu JT, Bao SP and Xu WB. Polyethylene/maleic anhydride grafted polyethylene/organic-montmorillonite nanocomposites. I. Preparation, microstructure, and mechanical properties. Journal of Applied Polymer Science. 2004; 91(6):3974-3980. http://dx.doi.org/10.1002/ app. 13612

32. Bartczak Z, Argon AS, Cohen RE and Weiberg M. Toughness mechanism in semi-crystalline polymer blends. Polymer. 1999; 40(9):2347-2365. http://dx.doi.org/10.1016/ S0032-3861(98)00444-3

33. Sternstein $\mathrm{S}$ and Zhu AJ. Reinforcement mechanism of nanofilled polymer melts as elucidated by nonlinear viscoelastic 
behavior. Macromolecules. 2002; 35(19):7262-7273. http:// dx.doi.org/10.1021/ma020482u

34. Vacatello M. Chain dimension in filled polymers: an intriguing problem. Macromolecules. 2002; 35(21):8191-8193. http:// dx.doi.org/10.1021/ma020416s
35. Fu Q, Wang G and Liu C. Polyethylene toughened by $\mathrm{CaCO}_{3}$ particles: The interface behaviour and fracture mechanism in high density polyethylene/ $\mathrm{CaCO}_{3}$ blends. Polymer. 1995; 36(12):2397-2401. http://dx.doi. org/10.1016/0032-3861(95)97339-H 